Potravinarstvo Slovak Journal of Food Sciences vol. 15, 2021, p. 1093-1103

https://doi.org/10.5219/1693

Received: 12 August 2021. Accepted: 14 October 2021. Available online: 28 October 2021 at www.potravinarstvo.com (C) 2020 Potravinarstvo Slovak Journal of Food Sciences, License: CC BY 3.0

ISSN 1337-0960 (online)

\title{
ANTIBIOFILM AND ANTIOXIDANT ACTIVITY OF ROSMARINUS OFFICINALIS ESSENTIAL OIL
}

\author{
Lucia Galovičová, Petra Borotová, Veronika Valková, Miroslava Kačániová
}

\begin{abstract}
The aim of the work was to explore the antioxidant potential and antibiofilm activity of the Rosmarinus officinalis essential oil. The DPPH method was used to determine the antioxidant activity. The agar microdilution method was used to determine the minimum biofilm inhibiting concentration (MBIC). The MALDI-TOF MS Biotyper was used to evaluate the antibiofilm activity on the wood and glass surface. Vapor phase antimicrobial analysis was used to determine the effect on the food model. The antioxidant activity was $28.76 \% \pm 2.68 \%$. The MBIC for Stenotrophomonas maltophilia was $25 \mu \mathrm{L} . \mathrm{mL}^{-1}$ and for Bacillus subtilis $12.5 \mu \mathrm{L}$. $\mathrm{mL}^{-1}$. Analysis of the mass spectra of $S$. maltophilia revealed an inhibitory effect from the $5^{\text {th }}$, which persisted until the end of the experiment. Analysis of the mass spectra of $B$. subtilis showed an inhibitory effect from the $7^{\text {th }}$ of the experiment. The experiments showed an effect on both tested surfaces. The food model showed a more pronounced effect of the Rosmarinus officinalis essential oil against $B$. subtilis. We assume that the effect of the essential oil is to disrupt the polysaccharide structure of the biofilm and consequently reduce the resistance of the biofilm. We have established that MALDI-TOF MS Biotyper is a suitable tool for evaluating changes in biofilm structure and could find more significant application for the study of biofilms in food and clinical practice.
\end{abstract}

Keywords: biofilm; Stenotrophomonas maltophilia; Bacillus subtilis; essential oil; MALDI-TOF MS Biotyper

\section{INTRODUCTION}

In recent years, there has been a growing interest in research into essential oils and their applications in the food and human health. Essential oils are volatile aromatic substances that are obtained from glandular trichomes and other secretory structures of plants. Subsequently, they are distributed mainly on the surface of plant organs, especially flowers, leaves, stems, and roots. Essential oils and their ingredients are a safe alternative to chemical preservatives. They have biological activity that inhibits the growth of microorganisms (Zhang et al., 2020).

Rosemary (Rosmarinus officinalis) is a perennial aromatic herb native to the Mediterranean Sea. It belongs to the family Lamiaceae. $R$. officinalis is an important source of volatile and non-volatile bioactive compounds (Rahbardar et al., 2017). The main components of $R$. officinalis essential oil are camphor, camphene, 1,8 -cineole, $\beta$-thujene, $\alpha$-thujene, chrysanthantone, and $\beta$-cubebene. These compounds show a variety of biological activities, including antimicrobial, antioxidant, anti-inflammatory, and anticarcinogenic properties (Touazi et al., 2018). Due to its therapeutic effects, it was used in the Middle Ages for the treatment of various diseases and it was also used as a preservative and flavouring agent (Elyemni et al., 2019). Biofilms are defined as complex bacterial communities found in an exopolysaccharide matrix on both biotic and abiotic surfaces. Biofilm formation is usually a cyclic multistage process. It is necessary to understand this process to develop effective strategies to combat pathogenic biofilms (Khatoon et al., 2018). The issue of biofilm formation concerns many food sectors such as the dairy industry, poultry and red meat processing, and fresh products (Kocot and Olszewska, 2017).

Stenotrophomonas maltophilia plays an important role in the colonization of biotic and abiotic surfaces, which significantly increases its resistance to antibiotics. This opportunistic pathogen is the originator of many nosocomial infections (Pompilio et al., 2020). It is also often found in the food industry, for example in raw milk, fish products, vegetables, and also in drinking water reservoirs. The presence of $S$. maltophilia in food products causes deterioration and significantly endangers human health (Zhang et al., 2020).

Bacillus subtilis, a non-pathogenic, gram-positive bacterium, is one of the most studied biofilm-forming microorganisms. Its importance in the food industry lies in the formation of a colony biofilm at the water-air interface (Yahav et al., 2018). Under industrial conditions, biofilm formation leads to costly regular cleaning, equipment corrosion, and the production of extracellular enzymes by biofilm bacteria. Importantly, endospore-producing biofilm genera such as Bacillus can become a significant source of persistent contamination (Ranmadugala et al., 2017). 
The work was aimed to evaluate the antioxidant and antibiofilm activity of the essential oil Rosmarinus officinalis against Stenotrophomonas maltophilia and Bacillus subtilis. To evaluate the molecular profiles of biofilms on glass and wood after the application of $R$. officinalis essential oil using MALDI-TOF MS Biotyper. To evaluate the effectiveness of essential oil against biofilms in a food model (carrot, potato, apple) using the vapor phase antimicrobial analysis.

\section{Scientific hypothesis}

After studying the available literature, we assume the presence of bioactive substances and the antioxidant potential of the essential oil Rosmarinus officinalis. Given the available publications, we anticipate an antibiofilm effect against S. maltophilia and B. subtilis. We believe that the antibiofilm effect could also be manifested in the gas phase in the food model.

\section{MATERIAL AND METHODOLOGY \\ Samples}

Rosmarinus officinalis essential oil was purchased from the Slovak company Hanus s.r.o (Nitra, Slovakia). It was obtained by steam distillation of a flowering flower. The manufacturer states as the main components of the essential oil 1,8-cineole $38-55 \%$, camphor $5-15 \%, \alpha+\beta$ pinene $13-23 \%$, limonene $1-4 \%$, borneol $1-5 \%$. The sample was stored in the cold $\left(4^{\circ} \mathrm{C}\right)$ and in the dark throughout the analyses.

\section{Chemicals}

2,2-diphenyl-1-picrylhydrazyl (DPPH, Sigma Aldrich, Germany), Mueller Hinton Broth (MHB, Oxoid, Basingstoke, UK), Muller Hinton agar (MHA, Oxoid, Basingstoke, UK).

\section{Animals and Biological Material:}

Bacterial strains forming the biofilm of Stenotrophomonas maltophilia and Bacillus subtilis were obtained from the dairy industry in the Czech Republic. They were identified by $16 \mathrm{~S}$ rRNA sequencing and MALDI-TOF MS Biotyper.

\section{Instruments}

Glomax spectrophotometer (Promega Inc., Madison, USA), MALDI-TOF MS Biotyper (Bruker, Daltonics, Bremen, Germany).

\section{Laboratory Methods}

To determine the antioxidant activity of Rosmarinus officinalis essential oil, 2,2-diphenyl-1-picrylhydrazyl (DPPH, Sigma Aldrich, Germany) was used according to the method of Sánchez-Moreno, Larrauri and SauraCalixto (1998). It is a colorimetric method in which the deep purple colour of DPPH changes to yellow after scavenging free radicals. The colour change is detected by a spectrophotometer. For essential oil analysis, a stock solution of DPPH was prepared by weighing $0.0025 \mathrm{~g}$ of DPPH into $100 \mathrm{~mL}$ of ethanol (96\%). $3.9 \mathrm{~mL}$ of stock solution was pipetted into the tube and $0.1 \mathrm{~mL}$ of $R$. officinalis essential oil was added. The prepared mixture in triplicate was incubated at laboratory temperature in the dark place for 10 minutes. The absorbance of the sample was measured with Glomax spectrophotometer (Promega Inc., Madison, USA) at $515 \mathrm{~nm}$ and the average absorbance of the sample was calculated. The percentage of antioxidant activity was calculated according to the formula:

$$
\mathrm{AA} \%=[(\mathrm{A} 0-\mathrm{AAT}) / \mathrm{A} 0 \times 100]
$$

Where:

A0 - is the absorbance of the control reaction (DPPH radical); AAT - is the absorbance of tested sample.

Minimal Biofilm Inhibitory Concentration (MBIC) was determined according to Hassan et al. (2011). The bacterial suspensions were incubated in the Mueller Hinton Broth (MHB, Oxoid, Basingstoke, UK) under aerobic conditions for $24 \mathrm{~h}$ at $37^{\circ} \mathrm{C}$. After incubation, an inoculum with optical density of 0.5 McFarland standard was prepared. $100 \mu \mathrm{L}$ MHB and $50 \mu \mathrm{L}$ inoculum were pipetted into a 96-well microtiter plate. Subsequently, $100 \mu \mathrm{L}$ of essential oil was added to the first column of the microplate. Mixing with a pipette gave a two-fold dilution with concentrations from $400 \mu \mathrm{L} \cdot \mathrm{mL}^{-1}$ to $0.195 \mu \mathrm{L} \cdot \mathrm{mL}^{-1}$. MHB with essential oil was used as a negative control and MHB with bacterial inoculum was used as maximal growth control. After culturing for 24 hours at $37{ }^{\circ} \mathrm{C}$ in an aerostat, the supernatant was discarded, the wells were washed three times with $250 \mu \mathrm{L}$ of saline and allowed to dry for 30 minutes at laboratory temperature. After drying, the wells were stained with $200 \mu \mathrm{L}$ crystal violet $(0.1 \% \mathrm{w} / \mathrm{v})$ for 15 minutes. The plates were repeatedly washed with distilled water and allowed to dry. Subsequently, $200 \mu \mathrm{L}$ of $33 \%$ acetic acid was added to resolubilize the samples. Samples were measured on Glomax spectrophotometer (Promega Inc., Madison, USA) at $570 \mathrm{~nm}$. The concentration at which the absorbance was lower or equal to the negative control was determined as MBIC.

\section{Description of the Experiment}

\section{Sample preparation:}

The analysis of the developmental stages of the biofilm and the evaluation of the molecular differences on the glass and the wood were performed in the same way as in Kačániová et al. (2020a) using MALDI-TOF MS Biotyper (Bruker, Daltonics, Bremen, Germany).

The antibiofilm activity of $R$. officinalis in a food model was analysed by a vapor phase antimicrobial assay. The antibiofilm effect was analysed on potato, carrot, and apple. Vegetables and fruit were cut into $5 \mathrm{~mm}$ slices and washed with distilled water. A layer of Muller Hinton agar (MHA, Oxoid, Basingstoke, UK) was poured into $60 \mathrm{~mm}$ Petri dishes and lids. After the agar solidification, one slice of the sample was placed on the plates. S. maltophilia and $B$. subtilis were applied to the samples by stabbing. The essential oil was diluted in ethyl acetate to final concentrations of 500,250 , and $125 \mu \mathrm{g} \cdot \mathrm{mL}^{-1}$. A circle of sterile $55 \mathrm{~mm}$ diameter filter paper was placed in the lid. $100 \mu \mathrm{L}$ of the appropriate concentration of essential oil was pipetted onto the surface of the filter paper. The filter paper was allowed to dry for 1 minute to evaporate the ethyl acetate and the dishes were sealed. Petri dishes were incubated for 7 days at $37^{\circ} \mathrm{C}$. Inhibition of bacterial growth by the essential oil was expressed as a percentage of inhibition compared to the control, where the control represented $0 \%$ inhibition. Inhibition by more than $50 \%$ was considered effective.

Number of samples analyzed: biofilm18, food model 24

Number of repeated analyses: 3

Number of experiment replication: 3 


\section{Statistical analysis}

All analyses were performed in triplicate. Statistical variability of data was processed using Microsoft-Excel ${ }^{\circledR}$ software.

\section{RESULTS AND DISCUSSION}

The antioxidant activity of Rosmarinus officinalis essential oil was $28.76 \% \pm 2.68 \%$. Wang et al. (2008) in their work determined a free radical scavenging activity $62.45 \% \pm 3.42 \%$. Gachkar et al. (2007) found out, that antioxidant activity is $69.30 \%$. Kasparavičienè et al. (2013) determined the antioxidant activity of $R$. officinalis at $75.96 \% \pm 1.12 \%$. Hussain et al. (2010) found out free radical scavenging activity $33.60 \%$. Okoh, Sadimenko and Afolayan (2011) detected, that antioxidant activity is $48.80 \%$. Teneva et al. (2020) compared the antioxidant activity of essential oils from the leaves and flowers of $R$. officinalis. They recorded antioxidant activity in range 25 $-82 \%$. This variability was due to the different chemical composition of the essential oils. Mohammed et al. (2020) set the percentage of free radical scavenging at $44.50 \%$. Nie et al. (2020) determined free radical scavenging activity $39.50 \%$. Amjadi et al. (2020) determined the antioxidant activity of rosemary essential oil at $24.00 \% \pm 3.10 \%$. Kanth et al. (2018) examined the antioxidant activity at concentrations range $1250-25000 \mathrm{ppm}$ and found free radical scavenging activity $8.16-51.8 \%$. The differences between the individual findings may be due to different chemical composition of the essential oils and the different concentrations of the active substances. The authors agree that $R$. officinalis essential oil has increased antioxidant activity, and our findings confirm this.

The minimal biofilm inhibiting concentrations determined by us were $25 \mu \mathrm{L} . \mathrm{mL}^{-1}$ for Stenotrophomonas maltophilia and $12.5 \mu \mathrm{L} . \mathrm{mL}^{-1}$ for Bacillus subtilis. Vieira et al. (2017) determined MBIC for B. subtilis $20 \mu \mathrm{L} \cdot \mathrm{mL}^{-1}$. Elhariry et al. (2013) determined MBIC of rosemary $12 \mu \mathrm{L} \cdot \mathrm{mL}^{-1}$ for the genera Bacillus and Pseudomonas. Jardak et al. (2017) investigated the antibiofilm activity against $S$. epidermidis and recorded an effect at oncentration $25 \mu \mathrm{L} \cdot \mathrm{mL}^{-1}$. Kanth et al. (2018) determined the MBIC for the biofilm of L. monocytogenes and S. aureus at $1.25 \mu \mathrm{L} \cdot \mathrm{mL}^{-1}$. Quave et al. (2008) tested the antibiofilm effect of rosemary on S. aureus and determined MBIC $8 \mu \mathrm{L} \cdot \mathrm{mL}^{-1}$. Ceylan et al. (2014) evaluated the antibiofilm activity of rosemary on S. aureus and determined MBIC $1.25 \mu \mathrm{L} \cdot \mathrm{mL}^{-1}$. Nasr-Eldin, Abdelhamid and Baraka (2017) focused on the antibiofilm effect of essential oil on S. aureus and found MBIC $10 \mu \mathrm{L} \cdot \mathrm{mL}^{-1}$. Rahnama et al. (2019) tested antibiofilm activity on B. cereus with MBIC $5 \mu \mathrm{L} \cdot \mathrm{mL}^{-1}$. Miladi et al. (2016) determined MBIC $25 \mu \mathrm{L} \cdot \mathrm{mL}^{-1}$ for the genus Salmonella in their work. All authors agree that Rosmarinus officinalis essential oil has significant antibiofilm effect. Different minimum inhibitory concentrations are due to different origins of essential oils with different chemical compositions and because they were tested on different strains of bacteria.

Analysis of the mass spectra of Stenotrophomonas maltophilia showed that on the third day of the experiment (Figure 1A), the similarity between the experimental spectra (wood and glass) and the control planktonic spectrum was maintained. On the fifth day of the experiment (Figure 1B), we recorded a gradual change in the experimental spectra compared to the control planktonicspectrum. The same trend was observed on the seventh day of the experiment (Figure 1C). On the ninth day of the experiment (Figure 1D) there was a decrease in the number of peaks in the experimental groups compared to the planktonic spectrum. The decrease was maintained on the twelfth day (Figure 1E) as well as the difference compared to the planktonic spectrum. On the last day (Figure 1F) of the experiment, there was an increase in the number of peaks in the experimental group compared to days 9 and 12, while maintaining the difference from the planktonic spectrum. The results show the inhibitory effect of the essential oil Rosmarinus officinalis on the structure of the biofilm.

The S. maltophilia dendrogram (Figure 2) is divided into two main clusters and 5 subclusters. In the constructed dendrogram, it is possible to observe the grouping primarily to the time point of view of the analysed samples. The planktonic spectrum showed the most significant relationship with the experimental group on day 3 of the experiment in MSP distance. The control groups showed shorter MSP distances, and thus higher similarity of spectra from planktonic cells than the experimental groups in the following days. This finding confirms the inhibitory effect of $R$. officinalis essential oil.

Analysis of the mass spectra of Bacillus subtilis showed that on days 3 and 5 of the experiment (Figures $3 \mathrm{~A}$ and 3B), the similarity between the experimental and planktonic spectra was maintained. On day 7 of the experiment, the difference between the experimental and control groups began to show (Figure 3C). On the ninth and twelfth days of the experiment (Figures 3D and $3 \mathrm{E}$ ), the change in experimental spectra compared to the control planktonic spectrum continued. On the last day of the experiment (Figure 3F), the most significant difference between the experimental and control groups was noted. These findings confirm the inhibitory effect of the essential oil on the structure of the $B$. subtilis biofilm.

The B. subtilis dendrogram (Figure 4) consists of two main clusters, and it is possible to observe that analysed samples were grouped primarily according to time progression. The most significant similarity of the planktonic spectrum with the experimental group was recorded on days 3 and 5 of the experiment. All control groups were in the same cluster as the planktonic cells. Experimental groups from day 7 were divided into a separate cluster. This finding confirms the inhibitory effect of $R$. officinalis from day 7 of the experiment.

Pereira et al. (2015) report that profiling with MALDITOF MS Biotyper is a very useful tool. Their results showed that the MALDI-TOF MS Biotyper approach is sufficiently sensitive to detect phenotypic changes in biofilm progression and can detect differences in biofilms cultured on different surfaces. Lo and Chang (2014) stated that the MALDI-TOF MS Biotyper is suitable for the investigation and identification of clinical isolates, including biofilmforming ones. Gaudreau et al. (2018) found that the MALDI-TOF MS Biotyper is useful for biofilm studies. Hasan, Gopal and Wu (2011) confirm the suitability of the MALDI-TOF MS Biotyper method for biofilm analysis. Kačániová et al. (2020a) analysed the effect of Coriandrum sativum essential oil on the inhibition of S. maltophilia and B. subtilis biofilm with positive effect. 
(A)

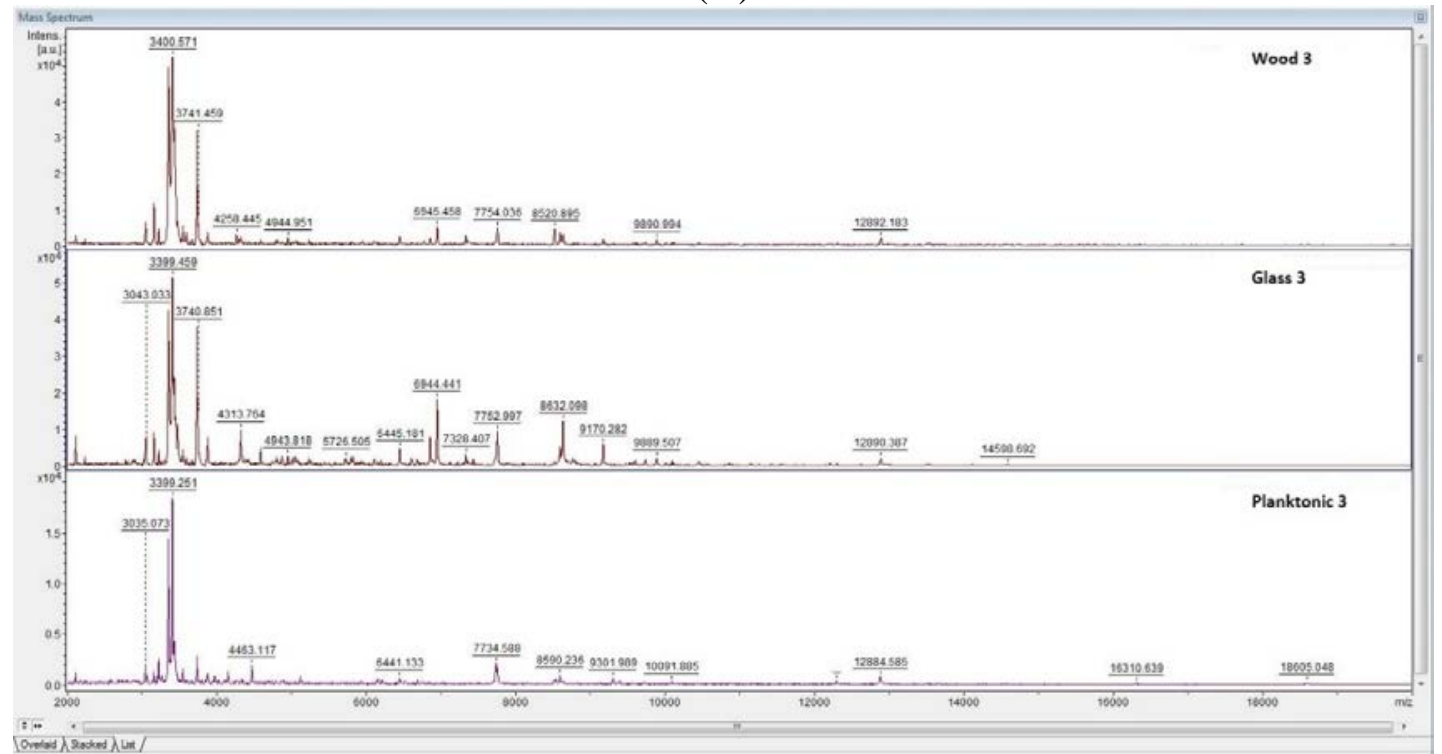

(B)

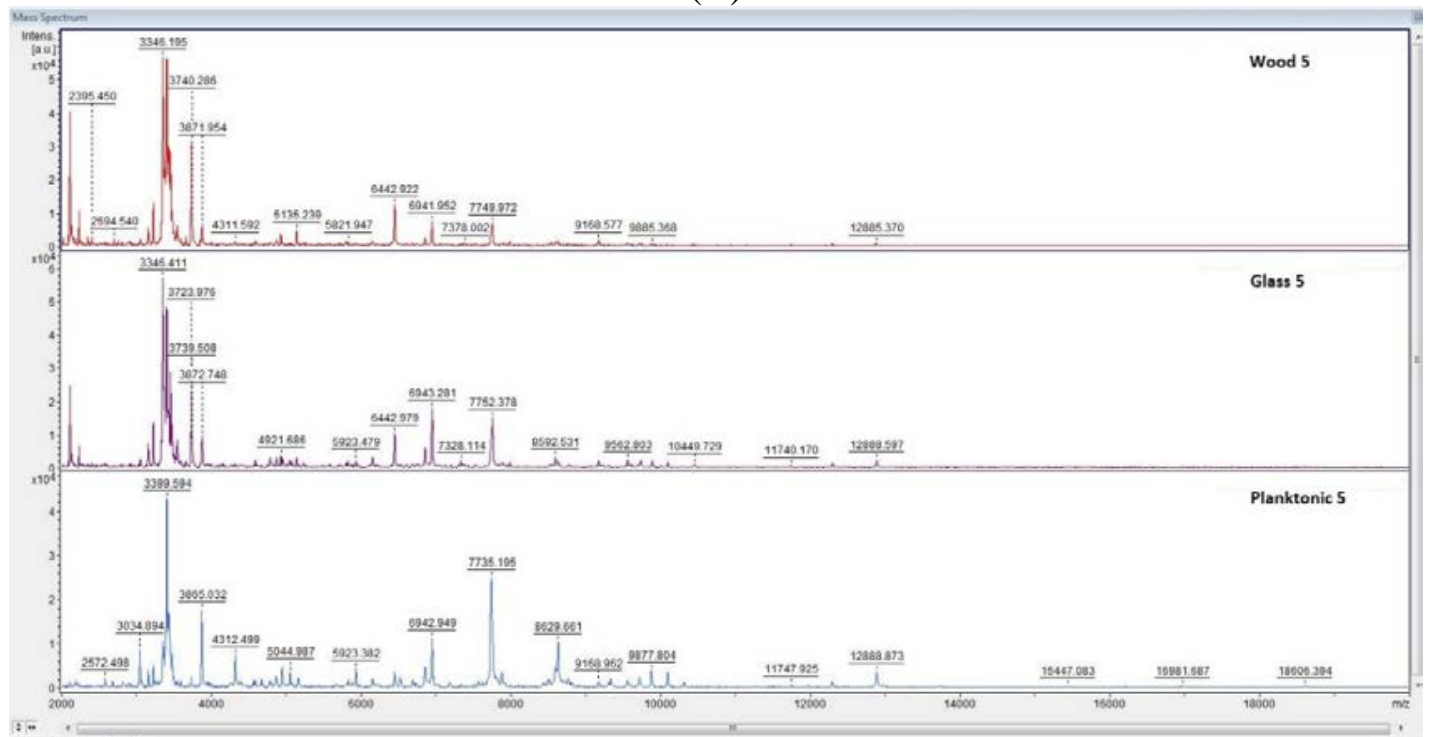

(C)

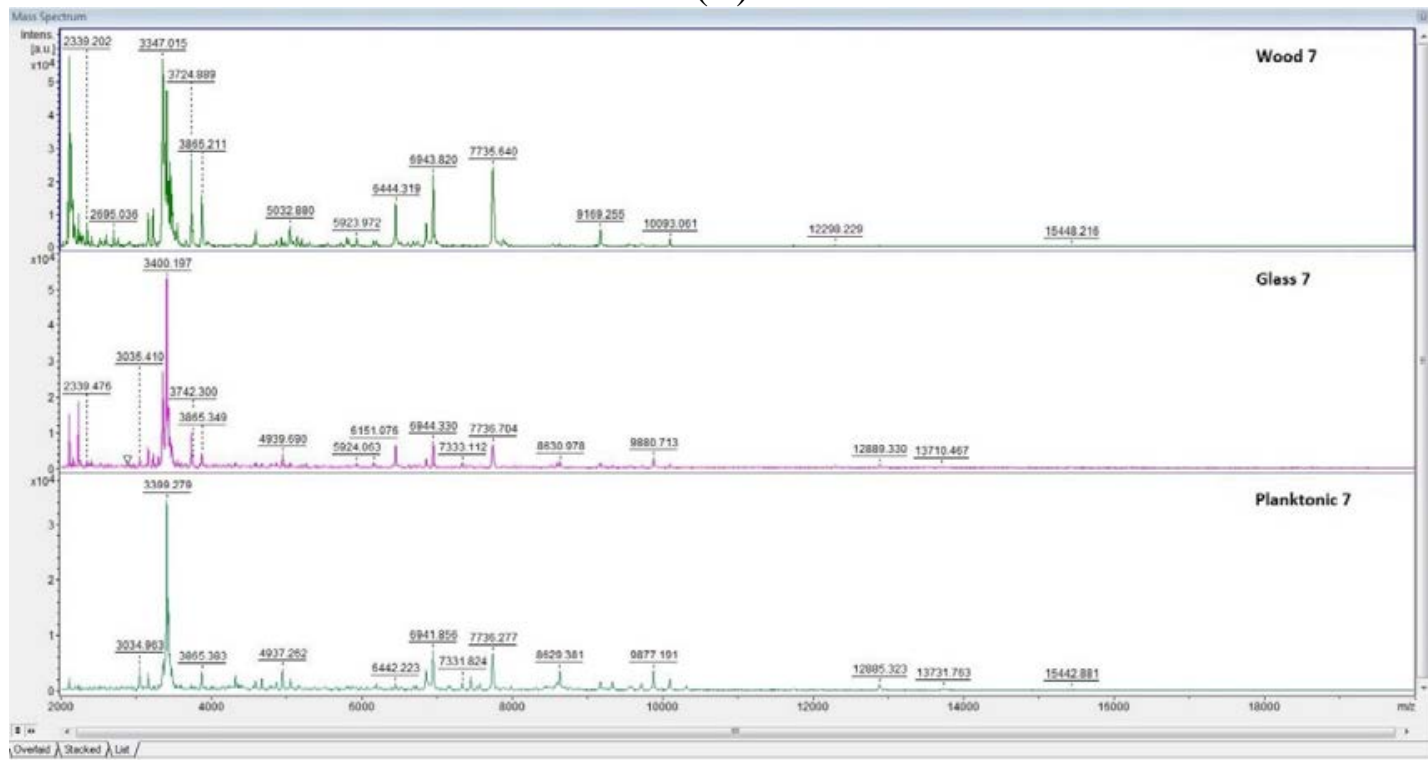

a.". 
(D)

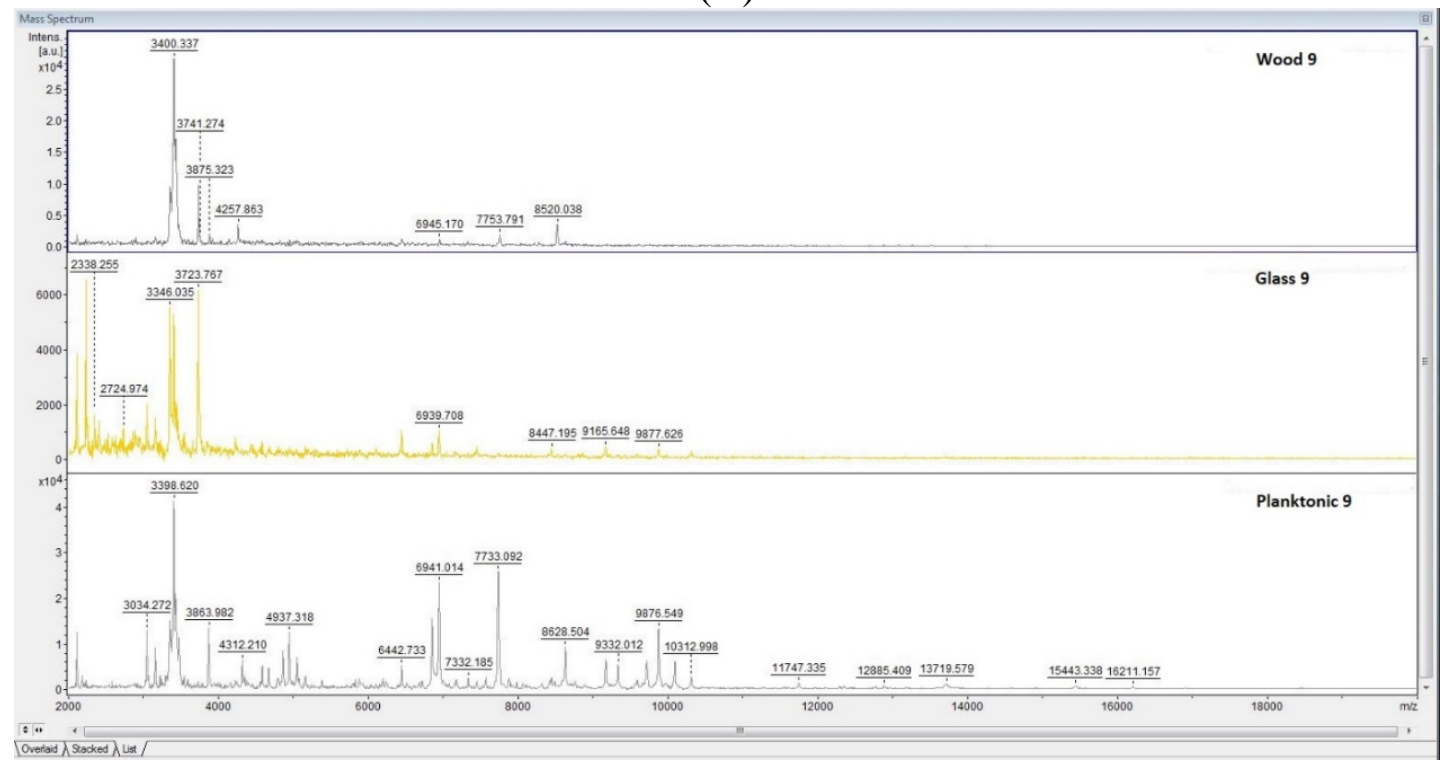

(E)

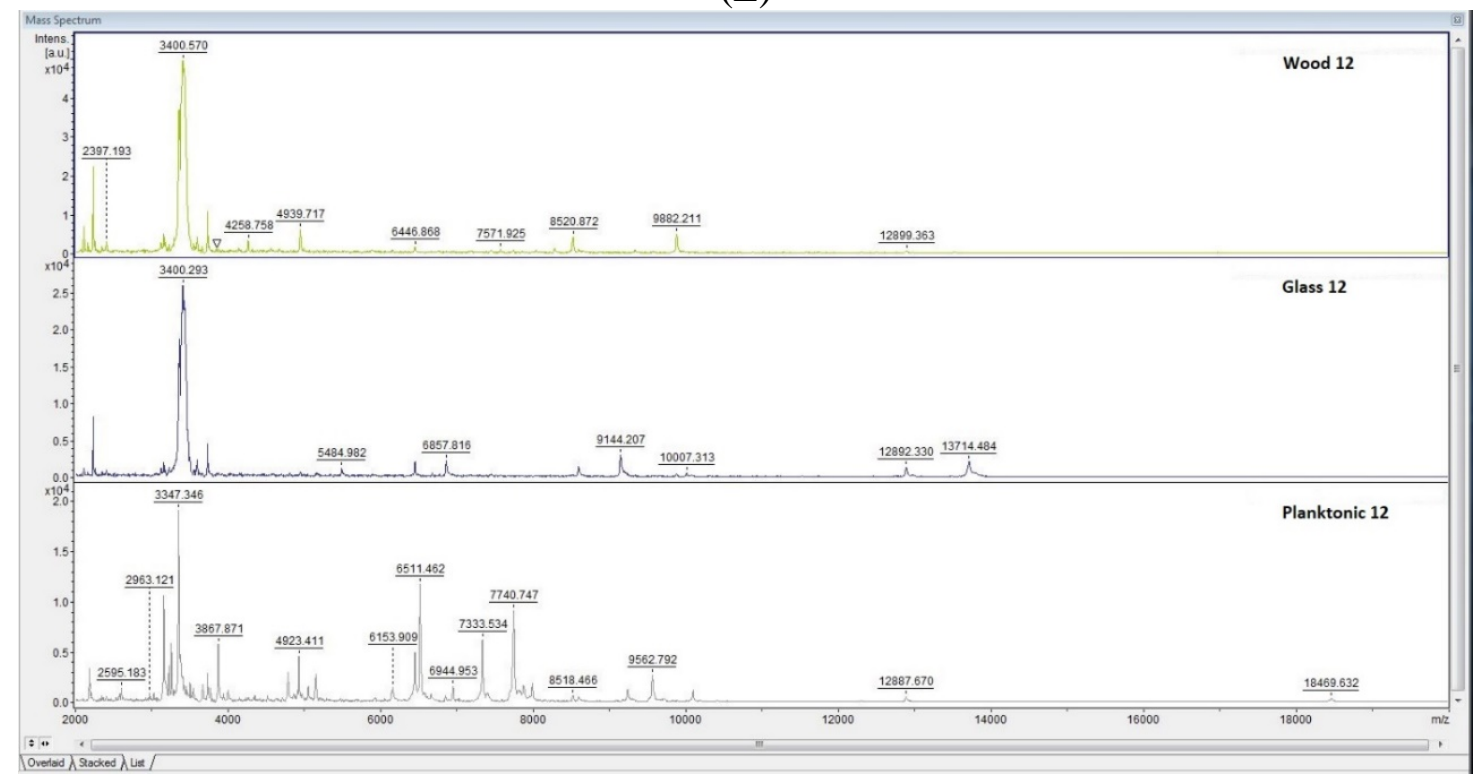

(F)

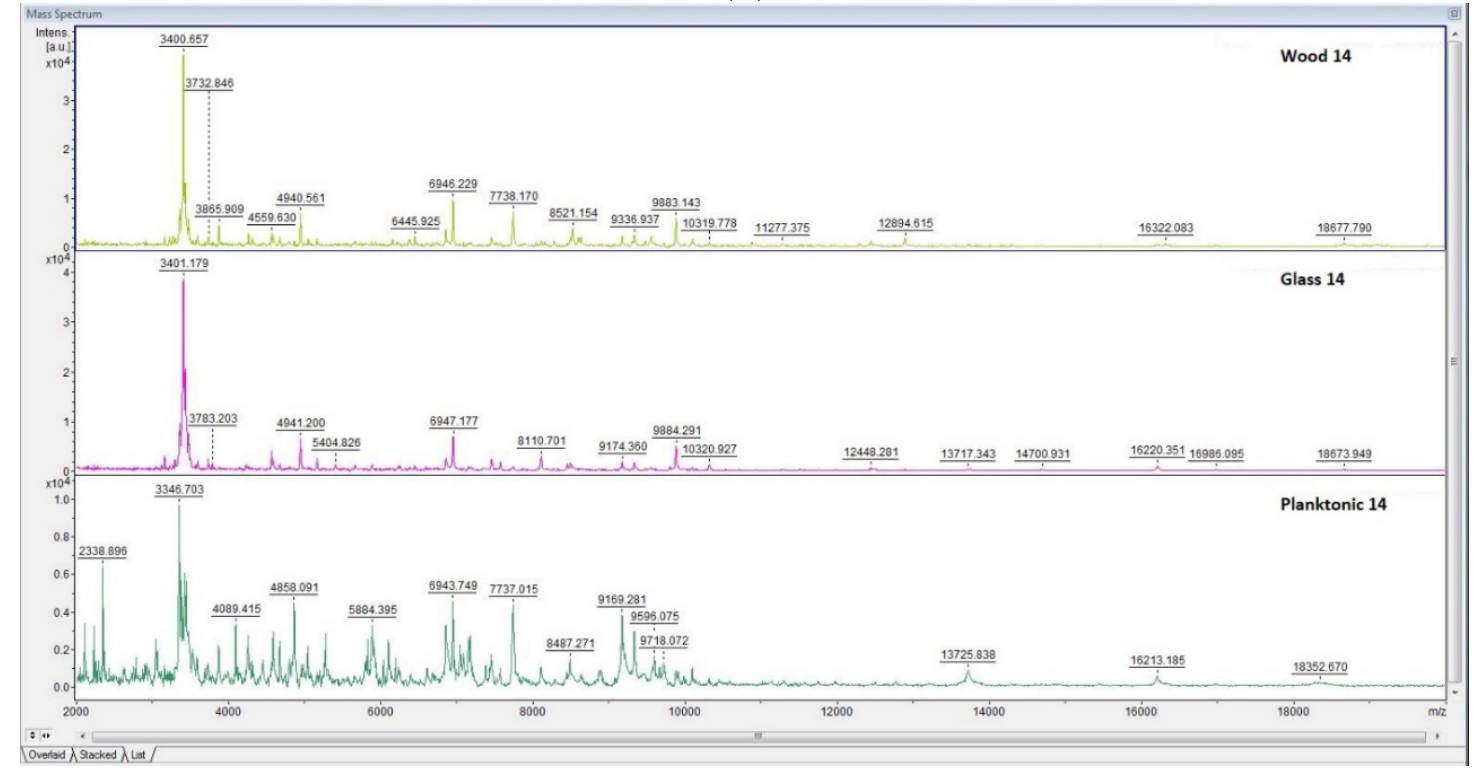

Figure 1 Representative MALDI-TOF mass spectra of S. maltophilia: (A) 3 days; (B) 5 days; (C) 7 days; (D) 9 days; (E) 12 days; and (F) 14 days. 


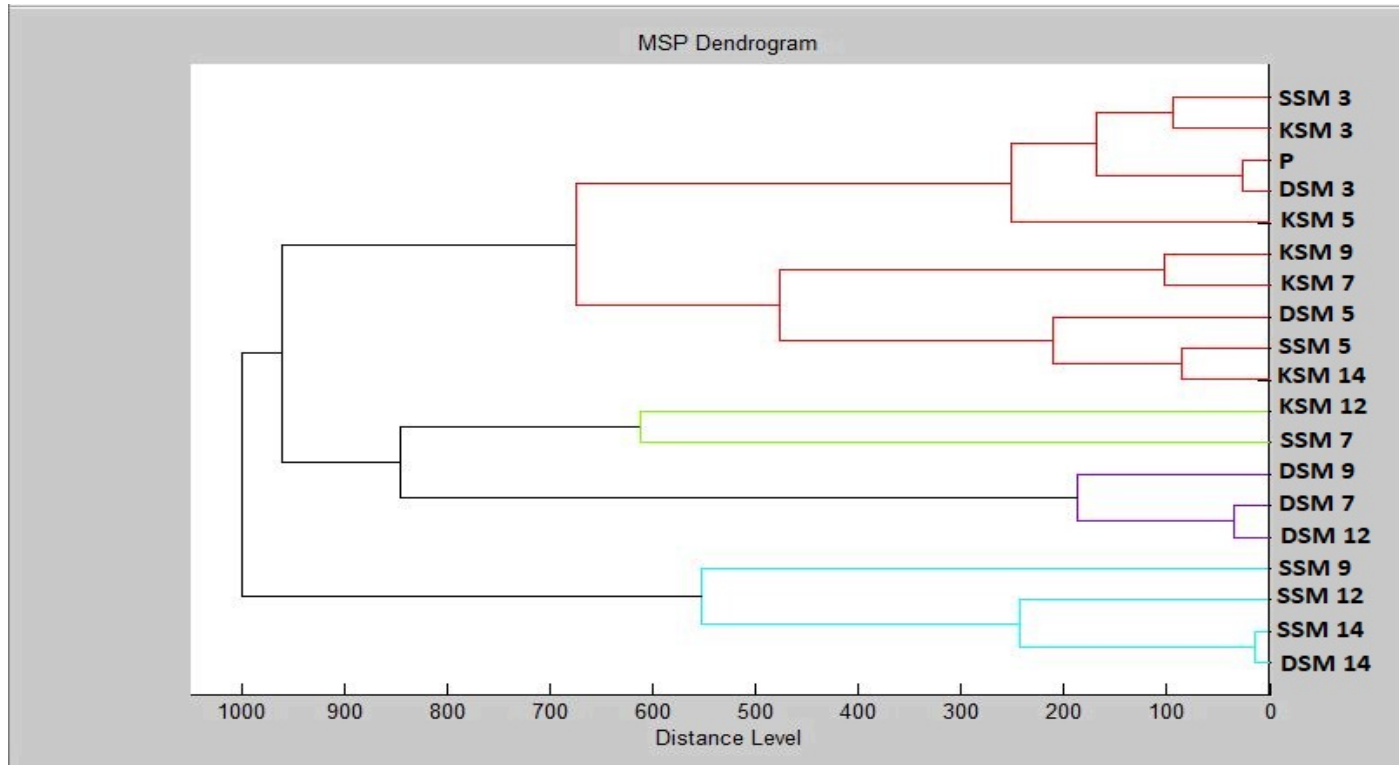

Figure 2 Dendrogram of $S$. maltophilia generated using the MSPs for all experimental group: SM - S. maltophilia; K - control; S - glass; D - wood; P - planktonic cell.

(A)

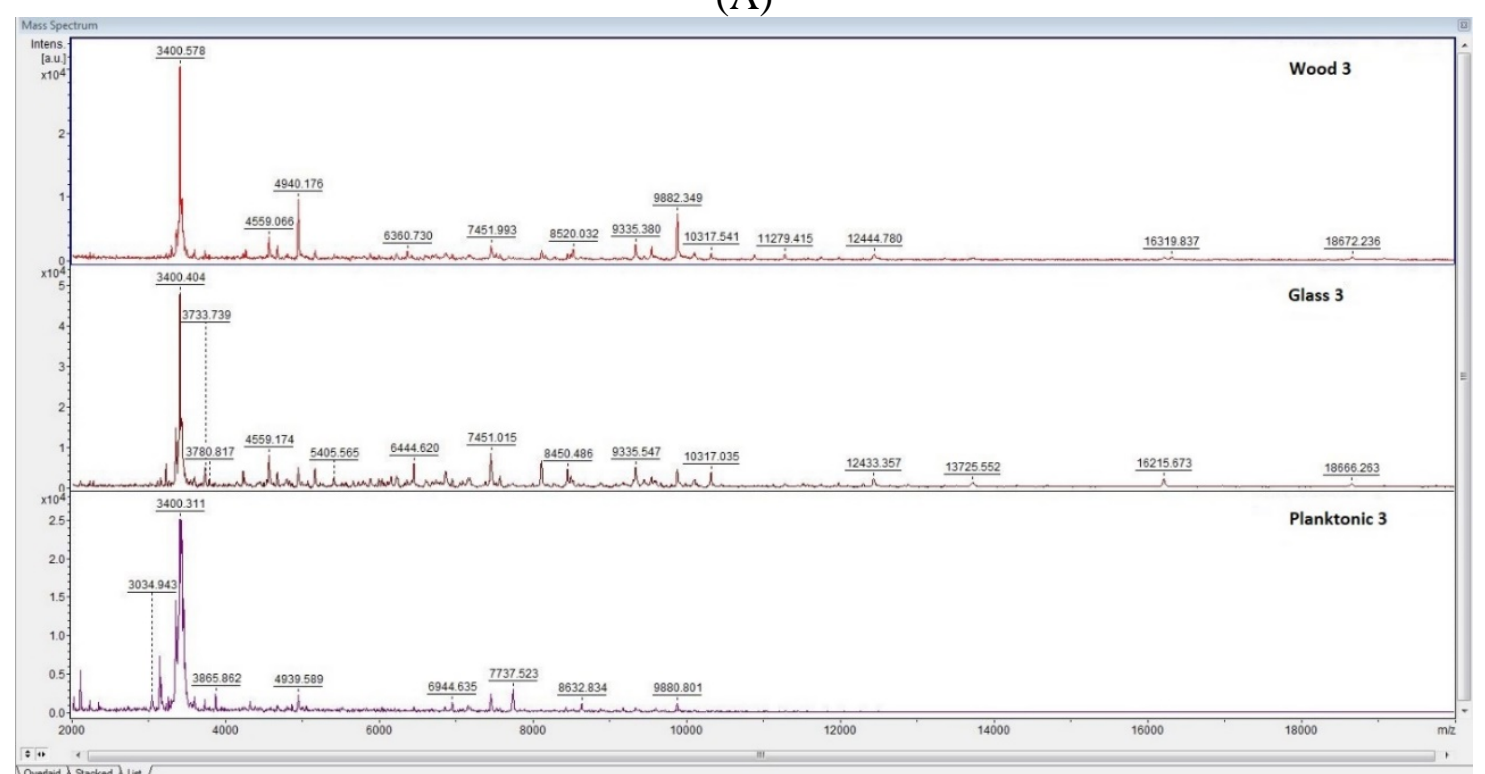

(B)

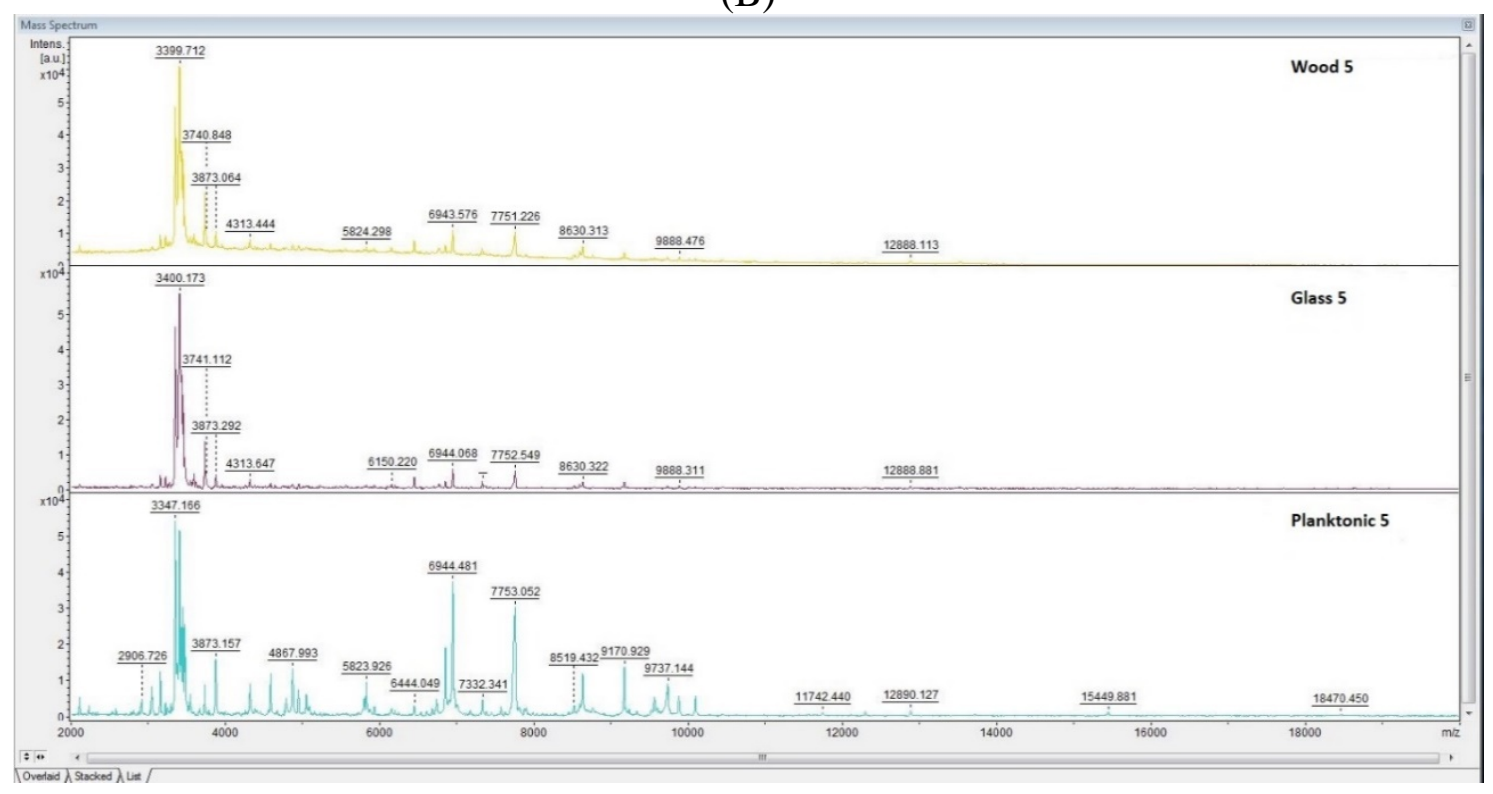


(C)

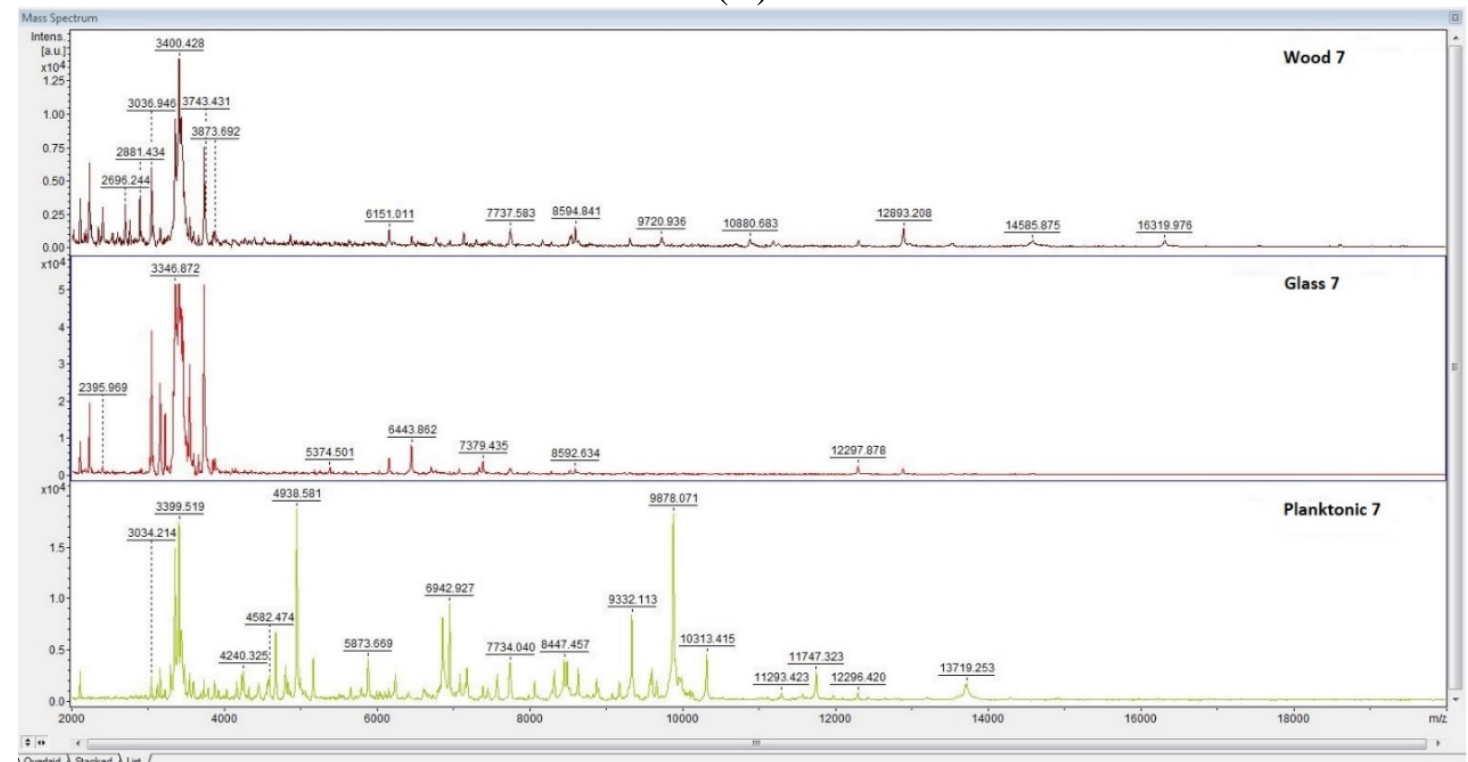

(D)

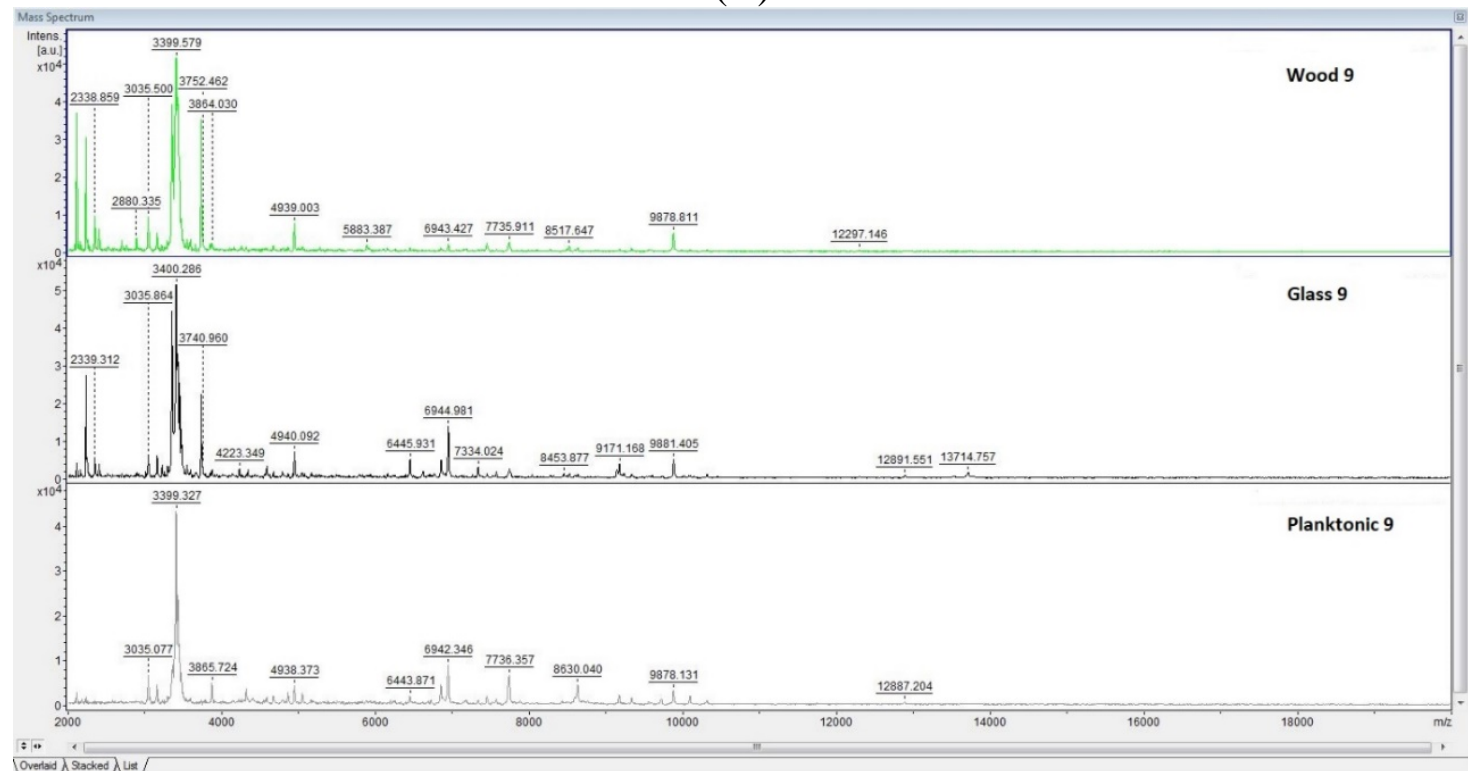

(E)

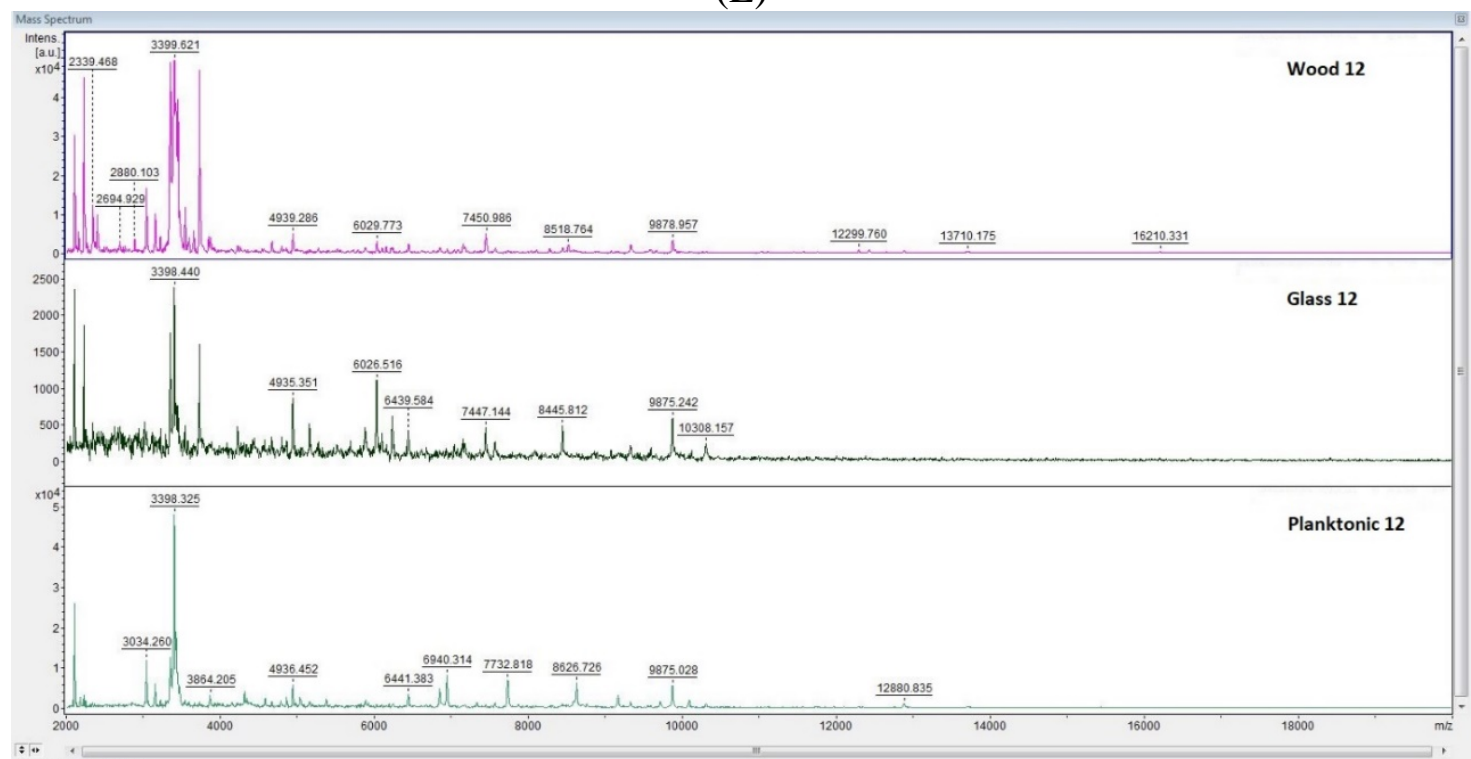

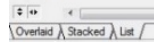


(F)

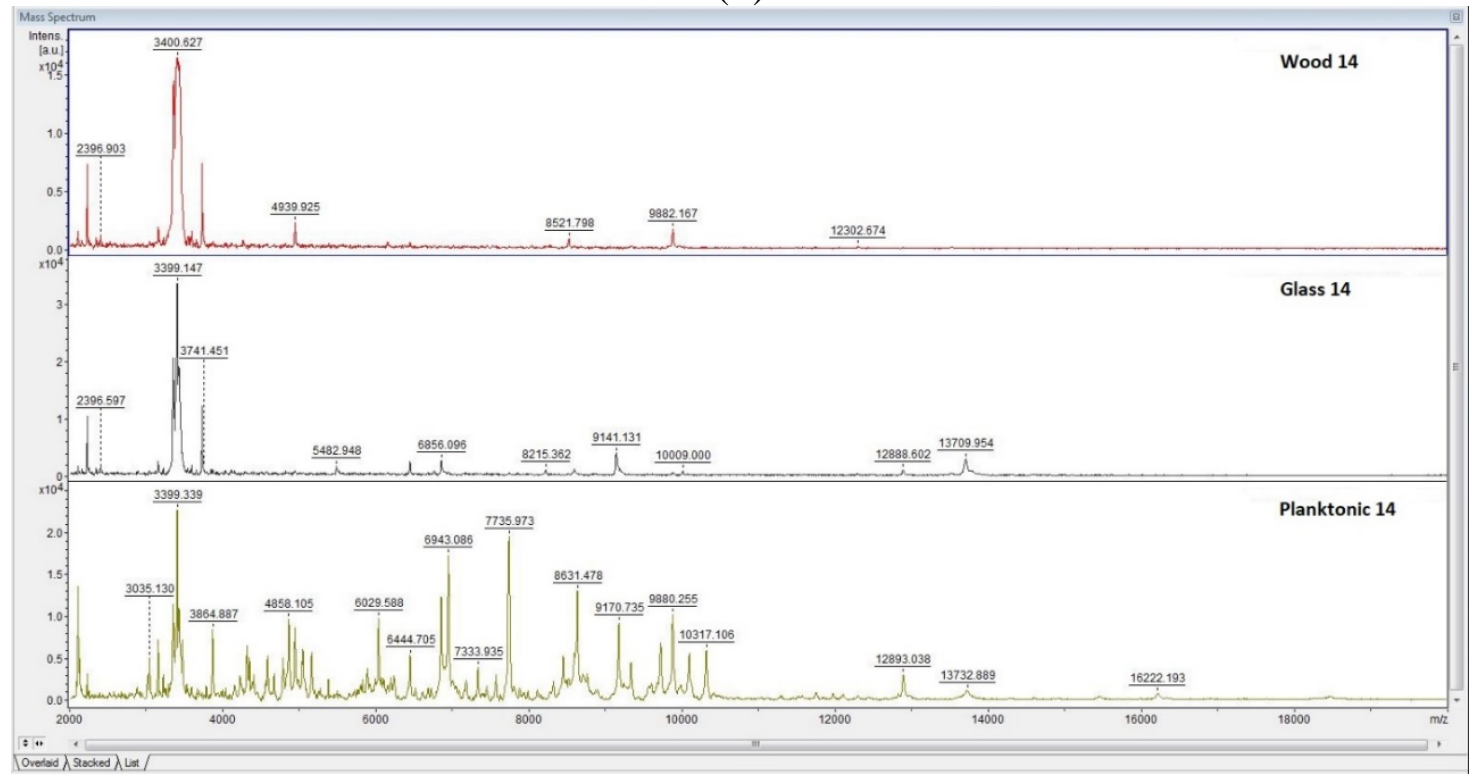

Figure 3 Representative MALDI-TOF mass spectra of B. subtilis: (A) 3 days; (B) 5 days; (C) 7 days; (D) 9 days; (E) 12 days; and (F) 14 days.

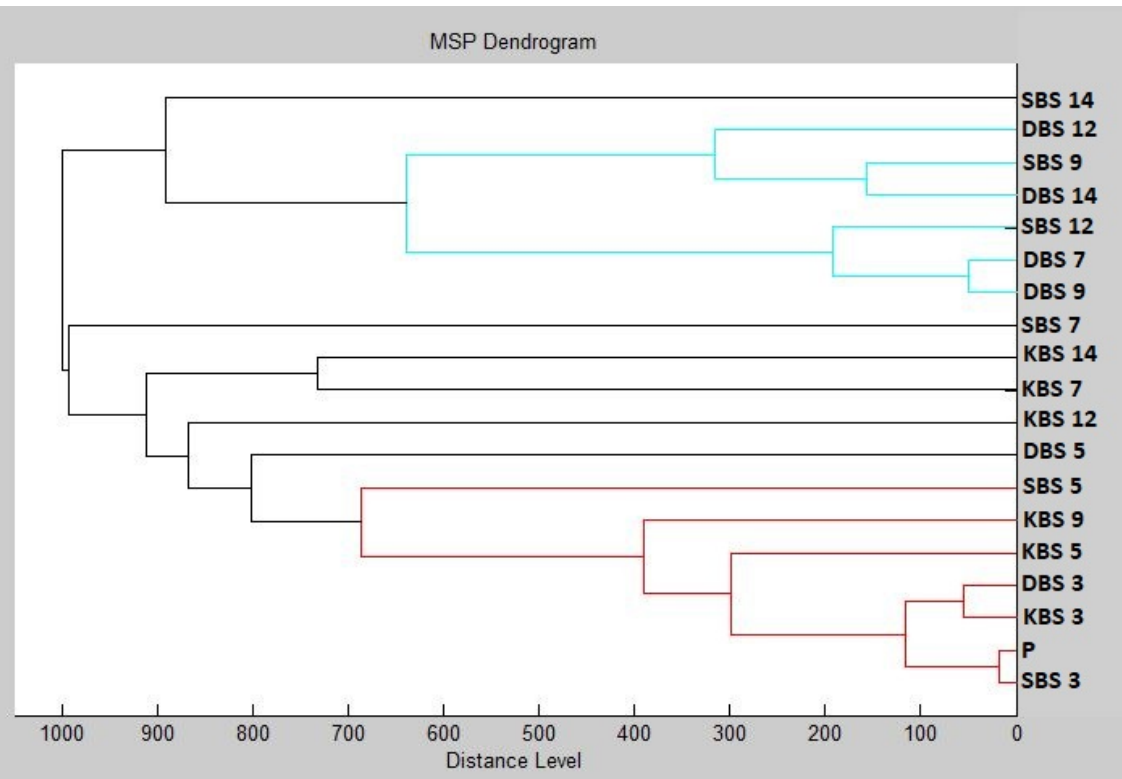

Figure 4 Dendrogram of B. subtilis generated using the MSPs for all experimental group: BS - B. subtilis; K. - control; $\mathrm{S}$ - glass; D - wood; P - planktonic cell.

Table 1 In situ antimicrobial analyses of vegetables and fruit with S. maltophilia in vapor phase with essential oil R. officinalis.

\begin{tabular}{|c|c|c|c|}
\hline $\begin{array}{c}\text { Concentration of EO } \\
\text { Food model }\end{array}$ & $125 \mu \mathrm{L} . \mathrm{L}^{-1}$ & $250 \mu \mathrm{L} . \mathrm{L}^{-1}$ & $500 \mu \mathrm{L} \cdot \mathrm{L}^{-1}$ \\
\hline Carrot & $50.78 \pm 2.59$ & $69.82 \pm 3.21$ & $87.80 \pm 1.41$ \\
\hline Potato & $24.36 \pm 2.11$ & $47.44 \pm 3.56$ & $79.92 \pm 1.27$ \\
\hline Apple & $42.56 \pm 2.28$ & $53.46 \pm 1.41$ & $85.45 \pm 1.69$ \\
\hline
\end{tabular}

Table 2 In situ antimicrobial analyses of vegetables and fruit with B. subtilis in vapor phase with essential oil R. officinalis.

\begin{tabular}{|c|c|c|c|}
\hline $\begin{array}{c}\text { Concentration of EO } \\
\text { Food model }\end{array}$ & $125 \mu \mathrm{L} . \mathrm{L}^{-1}$ & $250 \mu L . L^{-1}$ & $500 \mu \mathrm{L} . \mathrm{L}^{-1}$ \\
\hline Carrot & $20.39 \pm 1.21$ & $39.73 \pm 2.67$ & $67.42 \pm 1.32$ \\
\hline Potato & $62.53 \pm 2.52$ & $74.46 \pm 2.71$ & $92.48 \pm 1.83$ \\
\hline Apple & $64.56 \pm 1.33$ & $73.82 \pm 1.19$ & $89.35 \pm 1.87$ \\
\hline
\end{tabular}


In another work, Kačániová et al. (2020b) addressed the antibiofilm effect of Citrus aurantium essential oil by using MALDI-TOF MS Biotyper with positive result.

The results of the analysis of antibiofilm activity in the food model show that the essential oil of $R$. officinalis showed an inhibitory effect. The essential oil inhibited the growth of S. maltophilia on carrots by more than $50 \%$ (Table 1) at concentration $250 \mu \mathrm{g} \cdot \mathrm{mL}^{-1}$. The effect was observed on potato at $500 \mu \mathrm{g} \cdot \mathrm{mL}^{-1}$ and apple at concentration $250 \mu \mathrm{g} \cdot \mathrm{mL}^{-1}$. The essential oil inhibited the growth of $B$. subtilis by more than $50 \%$ (Table 2 ) on carrots at concentration $500 \mu \mathrm{g} \cdot \mathrm{mL}^{-1}$. The effect on potato and apple was already manifested at concentration $125 \mu \mathrm{g} \cdot \mathrm{mL}^{-1}$. Laird and Phillips (2011) report that vapor phase essential oils are effective antimicrobial systems and have advantages over the use of liquid phase essential oils. Kačániová et al. (2020b) used this method in their work to determine the antifungal activity of the essential oil Citrus aurantium.

\section{CONCLUSION}

The work confirmed the antioxidant potential of Rosmarinus officinalis essential oil using the DPPH method. The findings suggest that the essential oil has significant effect on biofilm inhibition. This effect was confirmed by the change in biofilm structure recorded by the MALDI-TOF MS Biotyper and by vapor phase inhibition in a food model. It is believed that the effect of the essential oil is to disrupt the polysaccharide structure of the biofilm and consequently reduce the resistance of the biofilm. MALDI-TOF Biotyper is a suitable tool for evaluating changes in biofilm structure. It could find more significant application for the study of biofilms in the food and clinical practice.

\section{REFERENCES}

Amjadi, S., Almasi, H., Ghorbani, M., Ramazani, S. 2020. Reinforced ZnONPs/ rosemary essential oil-incorporated zein electrospun nanofibers by $\kappa$-carrageenan. Carbohydrate Polymers, vol. 232, no. 15, p. 115800. https://doi.org/10.1016/j.carbpol.2019.115800

Ceylan, O., Uğur, A., Saraç, N., Ozcan, F., Baygar, T. 2014. The in vitro antibiofilm activity of Rosmarinus officinalis L. essential oil against multiple antibiotic resistant Pseudomonas sp. and Staphylococcus sp. Journal of Food, Agriculture \& Environment, vol. 12, no. 3-4, p. 82-86.

Elhariry, H., Abuzaid, A. A., Khiralla, G. M., Gherbawy, Y. 2013. Antibiofilm formation and anti-adhesive (to HEp-2 cells) effects of rosemary water extract against some food-related pathogens. International Journal of Food Science \& Technology, vol. 49, no. 4, p. 1132-1141. https://doi.org/10.1111/ijfs.12409

Elyemni, M., Louaste, B., Nechad, I., Elkamli, T., Bouia, A., Taleb, M., Chaouch, M., Eloutassi, N. 2019. Extraction of Essential Oils of Rosmarinus officinalis L. by Two Different Methods: Hydrodistillation and Microwave Assisted Hydrodistillation. Scientific World Journal, vol. 2019, no. 1. p. 1-6. https://doi.org/10.1155/2019/3659432

Gachkar, L., Yadegari, D., Rezaei, M. B., Taghizadeh, M., Astaneh, S. A., Rasooli, I. 2007. Chemical and biological characteristics of Cuminum cyminum and Rosmarinus officinalis essential oils. Food Chemistry, vol. 102, no. 3, p. 898-904. https://doi.org/10.1016/j.foodchem.2006.06.035
Gaudreau, A. M., Labrie, J., Goetz, C., Dufour, S., Jacques, M. 2018. Evaluation of MALDI-TOF mass spectrometry for the identification of bacteria growing as biofilms. Journal of Microbiological Methods, vol. 145, no. 1, p. 79-81. https://doi.org/10.1016/j.mimet.2018.01.003

Hasan, N., Gopal, J., Wu, H. F. 2011. Rapid, sensitive and direct analysis of exopolysaccharides from biofilm on aluminum surfaces exposed to sea water using MALDITOF MS. Journal of Mass Spectrometry, vol. 46, no. 11, p. 1160-1167. https://doi.org/10.1002/jms.2003

Hassan, A., Usman, J., Kaleem, F., Omair, M., Khalid, A.,Iqbal, M. 2011. Evaluation of different detection methods of biofilm formation in the clinical isolates. Brazilian Journal of Infectious Diseases, vol. 15, no. 4, p. 305-311. https://doi.org/10.1590/S1413-86702011000400002

Hussain, A. I., Anwar, F., Chatha, A. S. S., Jabbar, A., Mahboob, S., Nigam, P. S. 2010. Rosmarinus officinalis essential oil: antiproliferative, antioxidant and antibacterial activities. Brazilian Journal of Microbiology, vol. 41, no. 4. p. 1070-1078.

https://doi.org/10.1590/S1517$\underline{83822010000400027}$

Jardak, M., Elloumi-Mseddi, J., Aifa, S., Mnif, S. 2017. Chemical composition, anti-biofilm activity and potential cytotoxic effect on cancer cells of Rosmarinus officinalis L. essential oil from Tunisia. Lipids Health and Disease, vol. 16, no. 190. https://doi.org/10.1186/s12944-017-0580-9

Kačániová, M., Galovičová, L., Ivanišová, E., Vukovic, N. L., Štefániková, J., Valková, V., Borotová, P., Žiarovská, J., Terentjeva, M., Felšöciová, S., Tvrdá, E. 2020a. Antioxidant, Antimicrobial and Antibiofilm Activity of Coriander (Coriandrum sativum L.) Essential Oil for Its Application in Foods. Foods, vol. 9, no. 3, p. 282. https://doi.org/10.3390/foods9030282

Kačániová, M., Terentjeva, M., Galovičová, L., Ivanišová, E., Štefániková, J., Valková, V., Borotová, P., Kowalczewski, P. Ł., Kunová, S., Felšöciová, S., Tvrdá, E., Žiarovská, J., Prokeinová, R. B., Vukovic, N. 2020b. Biological Activity and Antibiofilm Molecular Profile of Citrus aurantium Essential Oil and Its Application in a Food Model. Molecules, vol. 25, no. 7, p. 3956. https://doi.org/10.3390/molecules25173956

Kanth, M. K., Mehta, N., Chatli, M. K., Malav, O. P., Kumar, P., Wagh, R. V., Panwar, H. 2018. In-vitro Assessment of Antimicrobial, Antibiofilm and Antioxidant Potential of Essential Oil from Rosemary (Rosmarinus officinalis L. Journal of Animal Research, vol. 8, no. 6, p. 989-998. http://doi.org/10.30954/2277-940X.12.2018.7

Kasparavičienė, G., Ramanauskienė, K., Savickas, A., Velžienè, S., Kalvėnienè, Z., Kazlauskienè, D., Ragažinskienè, O., Ivanauskas, K. 2013. Evaluation of total phenolic content and antioxidant activity of different Rosmarinus officinalis L. ethanolic extracts. Biologija, vol. 59, no. $1, \quad$ p. $39-44$. https://doi.org/10.6001/biologija.v59i1.2650

Khatoon, Z., McTiernan, C. D., Suuronen, E. J., Mah, T. F., Alarcon, E. I. 2018. Bacterial biofilm formation on implantable devices and approaches to its treatment and prevention. Heliyon, vol. 4, no. 12, p. e01067. https://doi.org/10.1016/j.heliyon.2018.e01067

Kocot, A. M., Olszewska, M. A. 2017. Biofilm formation and microscopic analysis of biofilms formed by Listeria monocytogenes in a food processing context. $L W T$, vol. 84, no. 1, p. 47-57. https://doi.org/10.1016/j.lwt.2017.05.042

Laird, K., Phillips, C. 2011. Vapour phase: a potential future use for essential oils as antimicrobials? Letters in Applied 
Microbiology, vol. 54, no. 3, p. 169-174. https://doi.org/10.1111/j.1472-765X.2011.03190.x

Lo, H. H., Chang, S. M. 2014. Identification, characterization, and biofilm formation of clinical Chryseobacterium gleum isolates. Diagnostic Microbiology and Infectious Disease, vol. 79, no. 3, p. 298-302. https://doi.org/10.1016/j.diagmicrobio.2014.01.027

Miladi. H., Mili, D., Slama, R. B., Zouari, S., Ammar, B., Bakhrouf, A. 2016. Antibiofilm formation and anti-adhesive property of three mediterranean essential oils against a foodborne pathogen Salmonella strain. Microbial Pathogenesis, vol. 93, no. 1, p. 22-31. https://doi.org/10.1016/j.micpath.2016.01.017

Mohammed, H. A., Al-Omar, M. S,. Mohammed, S. A. A., Aly, M. S. A., Alsuqub, A. N. A., Khan, R.A. 2020. Drying Induced Impact on Composition and Oil Quality of Rosemary Herb, Rosmarinus Officinalis Linn. Molecules, vol. 25, no. 12, p. 2830. https://doi.org/10.3390/molecules25122830

Nasr-Eldin, M. A., Abdelhamid, A. G., Baraka, D. M. 2017. Antibiofilm and Antiviral Potential of Leaf Extracts from Moringa oleifera and Rosemary (Rosmarinus officinalis Lam.). Egyptian Journal of Microbiology, vol. 52, no. 1, p. 129-139. https://doi.org/10.21608/EJM.2017.1439.1027

Nie, J. Y., Li, R., Jiang, Z. T., Wang, Y., Tan, J., Tang, S. H. and Zhang, Y.2020. Antioxidant activity screening and chemical constituents of the essential oil from rosemary by ultra-fast GC electronic nose coupled with chemical methodology. Journal of the Science of Food and Agriculture, vol. 100, no. 8, p. 3481-3487. https://doi.org/10.1002/jsfa.10388

Okoh, O. O., Sadimenko, A. P., Afolayan, A. J. 2011. Antioxidant activities of Rosmarinus officinalis L. essential oil obtained by hydro-distillation and solvent free microwave extraction. African Journal of Biotechnology, vol. 10, no. 20, p. 4207-4211.

Pereira, F. D. E. S., Bonattoa, C. C., Lopes, C. A. P., Pereira, A. L., Silva, L. P. 2015. Use of MALDI-TOF mass spectrometry to analyze the molecular profile of Pseudomonas aeruginosa biofilms grown on glass and plastic surfaces. Microbial Pathogenesis, vol. 86, no. 1, p. 3237. https://doi.org/10.1016/j.micpath.2015.07.005

Pompilio, A., Savini, V, Fiscarelli, E., Gherardi, G., Di Bonaventura, G. 2020. Clonal Diversity, Biofilm Formation, and Antimicrobial Resistance among Stenotrophomonas maltophilia Strains from Cystic Fibrosis and Non-Cystic Fibrosis Patients. Antibiotics, vol. 9, no. 1, p. 15-31. https://doi.org/10.3390/antibiotics9010015

Quave, C. L., Plano, L. R. W., Pantuso, T., Bennett, B. C. 2008. Effects of extracts from Italian medicinal plants on planktonic growth, biofilm formation and adherence of methicillin-resistant Staphylococcus aureus. Journal of Ethnopharmacology, vol. 118, no. 3, p. 418-428. https://doi.org/10.1016/j.jep.2008.05.005

Rahbardar, M. G., Amin, B., Mehri, S., Mirnajafi-Zadeh, S. J., Hosseinzadeh, H. 2017. Anti-inflammatory effects of ethanolic extract of Rosmarinus officinalis L. and rosmarinic acid in a rat model of neuropathic pain. Biomedicine \& Pharmacotherapy, vol. 86, no. 1, p. 441-449. https://doi.org/10.1016/j.biopha.2016.12.049

Rahnama, M., Fakheri, B. A., Mashhady, M. A., Saeidi, S. 2019. Anti-Bacterial and Anti-Biofilm Activity of Glycyrrhiza glabra, Rosmarinus officinalis and Saponaria officinalis Extracts on Important Food Pathogens. Gene, Cell and Tissue, vol. 6, no. 4, p. e96326. http://doi.org/10.5812/gct.96326
Ranmadugala, D., Ebrahiminezhad, A., Manley-Harris, M., Ghasemi, Y., Berenjian, A. 2017. The effect of iron oxide nanoparticles on Bacillus subtilis biofilm, growth and viability. Process Biochemistry, vol. 62, no. 1, p. 231-240. https://doi.org/10.1016/j.procbio.2017.07.003

Sánchez-Moreno, C., Larrauri, J. A., Saura-Calixto, F. 1998. A procedure to measure the antiradical efficiency of polyphenols. Journal of the Science of Food and Agriculture, vol. 76, no. 2, p. 270-276. https://doi.org/10.1002/(SICI)10970010(199802)76:2\%3C270::AID-JSFA945\%3E3.0.CO;2-9

Teneva, L. D. G., Goranov, B. G., Denkova-Kostova, R. S., Hristova-Ivanova, Y. M., Klisurova, D. I., Slavchev, A. K., Denkova, Z. R., Kostov, G. A. 2020. Chemical composition, antioxidant and antimicrobial activity of essential oils from leaves and flowers of Rosmarinus officinalis. Bulgarian Chemical Communications, vol. 52, no. 1, p. 54-59.

Touazi, L., Aberkane, B., Bellik, Y., Moula, N., IguerOuada, M. 2018. Effect of the essential oil of Rosmarinus officinalis (L.) on rooster sperm motility during $4{ }^{\circ} \mathrm{C}$ shortterm storage. Veterinary World, vol. 11, no. 5, p. 590-597. http://doi.org/10.14202/vetworld.2018.590-597

Vieira, M., Bessa, L. J., Martins, M. R., Arantes, S., Teixeira, A. P. S., Mendes, A., Costa, P. M., Belo, A. D. F. 2017. Chemical Composition, Antibacterial, Antibiofilm and Synergistic Properties of Essential Oils from Eucalyptus globulus Labill. and Seven Mediterranean Aromatic Plants. Chemistry \& Biodiversity, vol. 14, no. 6, p. e1700006. https://doi.org/10.1002/cbdv.201700006

Wang, W., Wu, Y. N., Zu, Y. G., Fu, Y. J. 2008. Antioxidative activity of Rosmarinus officinalis L. essential oil compared to its main components. Food Chemistry, vol. 108, no. 3, p. 1019-1022. https://doi.org/10.1016/j.foodchem.2007.11.046

Yahav, S., Berkovich, Z., Ostrov, I., Reifen, R., Shemesh, M. 2018. Encapsulation of beneficial probiotic bacteria in extracellular matrix from biofilm-forming Bacillus subtilis. International Journal, vol. 46, no. 2, p. 974-982. https://doi.org/10.1080/21691401.2018.1476373

Zhang, Y., Wei, J., Chen, H., Song, Z., Guo, H., Yuan, Y., Yue, T. 2020. Antibacterial activity of essential oils against Stenotrophomonas maltophilia and the effect of citral on cell membrane. LWT, vol. 117, no. 1, p. 108667. https://doi.org/10.1016/j.lwt.2019.108667

\section{Funding:}

This work was supported by the grant APVV-20-0058 “The potential of the essential oils from aromatic plants for medical use and food preservation.”

\section{Acknowledgments:}

This work has been supported by the grants of the VEGA no. $1 / 0180 / 20$.

\section{Conflict of Interest:}

The authors declare no conflict of interest.

\section{Contact address:}

*Lucia Galovičová, Department of Fruit Science, Viticulture and Enology, Faculty of Horticulture and Landscape Engineering, Tulipánová 7, 949 76, Nitra, Slovakia, Tel.: +421 907260 116,

E-mail: 1.galovicova95@gmail.com

ORCID: https://orcid.org/0000-0002-1203-4115 
Petra Borotová, Department of Animal Physiology, Faculty of Biotechnology and Food Sciences, Tr. A. Hlinku 2, 94976 Nitra, Slovakia, AgroBioTech Research Centre, Slovak University of Agriculture, Tr. A. Hlinku 2, 94976 Nitra, Slovakia, Tel.: +421 908131 305,

E-mail: petra.borotova@uniag.sk

ORCID: https://orcid.org/0000-0003-0278-4323

Veronika Valková, Department of Fruit Science, Viticulture and Enology, Faculty of Horticulture and Landscape Engineering, Tulipánová 7, 949 76, Nitra, Slovakia, AgroBioTech Research Centre, Slovak University of Agriculture, Tr. A. Hlinku 2, 94976 Nitra, Slovakia, Tel.: +421911633 386,

E-mail: veronika.valkova@uniag.sk

ORCID: https://orcid.org/0000-0001-7048-6323
Miroslava Kačániová, Department of Fruit Science, Viticulture and Enology, Faculty of Horticulture and Landscape Engineering, Tulipánová 7, 949 76, Nitra, Slovakia; Department of Bioenergetics, Food Analysis and Microbiology, Institute of Food Technology and Nutrition, University of Rzeszow, Cwiklinskiej 1, 35-601 Rzeszow, Poland, Tel.: +421 905499 166,

E-mail: kacaniova.miroslava@gmail.com

ORCID: https://orcid.org/0000-0002-4460-0222

Corresponding author: * 